\title{
Two cases of intraocular lymphoma diagnosed by analyses of vitreous and infusion fluid
}

\author{
Masato Matsuoka' \\ Hideyuki Yoshida' \\ Yuichi Kinoshita ${ }^{2}$ \\ Tetsuya Nishimura' \\ 'Department of Ophthalmology, \\ ${ }^{2}$ Department of Histopathology, \\ Kansai Medical University, Takii \\ Hospital, Osaka, Japan
}

This article was published in the following Dove Press journal:

Clinical Ophthalmology

3 April 2013

Number of times this article has been viewed
Correspondence: Masato Matsuoka Department of Ophthalmology, Kansai Medical University,

Fumizono-cho 10-15, Moriguchi, Osaka 570-8507, Japan

$\mathrm{Tel}+8 \mid 66992$ I00I ext 3324

Fax +8I 669932222

Email matsuokm@takii.kmu.ac.jp
Purpose: Intraocular lymphomas are rare, and they have poor prognosis. Thus, early diagnosis and treatment are needed. A definitive diagnosis of a lymphoma is based on cytological analysis of the intraocular fluids or tissues. We report two cases of intraocular lymphoma diagnosed by the analyses of vitreous and infusion fluid.

Patients: Case 1 was a 66-year-old woman who complained of eye floaters and was found to have diffuse vitreous opacification bilaterally. She received corticosteroid therapy, however the vitreous opacification was not resolved, and her visual acuity (VA) remained reduced. She underwent pars plana vitrectomy (PPV), and vitreous and infusion fluid were collected to determine the cause of the reduced VA. The undiluted vitreous obtained from core PPV was submitted for cytokine analysis, and infusion fluid was obtained from the machine cassette after full PPV and used for cytological analysis. Case 2 was a 62-year-old man referred with low vision and was found to have diffuse vitreous opacification in the right eye and dot hemorrhages in both eyes. Four years earlier, he had been diagnosed with diffuse large B-cell lymphoma of the paranasal sinuses and was in remission after chemotherapy. Because metastasis of the lymphoma was suspected, he underwent PPV, and intraocular samples were collected as in Case 1.

Results: Atypical lymphoid cells were detected from the infusion fluid in both cases. The ratio of interleukin (IL)-10 to IL-6 was greater than 1.0 in both cases. These results allowed us to make a diagnosis of intraocular lymphoma: primary intraocular lymphoma in Case 1 and metastatic intraocular lymphoma in Case 2.

Conclusion: Vitreous and infusion fluid collected during PPV can be used for diagnosing an intraocular lymphoma.

Keywords: intraocular lymphoma, cytological analysis, vitreous, pars plana vitrectomy, infusion fluid

\section{Introduction}

Intraocular lymphomas are rare, and they make up less than $1 \%$ of intraocular tumors ${ }^{1}$ and $1 \%$ of intraocular inflammations. ${ }^{2}$ Blurred vision and vitreous opacifications are the most common ocular symptoms and signs of an intraocular lymphoma. ${ }^{3}$ The lifetime prognosis of this disease is poor: ${ }^{4}$ the 5 -year survival rate is $61.1 \%$ in Japan. ${ }^{3}$ Thus, early diagnosis and treatment are needed.

A definitive diagnosis of an intraocular lymphoma is based on cytological findings of the intraocular fluid or tissues obtained from a biopsy or pars plana vitrectomy (PPV). ${ }^{5,6}$ However, cytological examination can be difficult because only a small amount of sample can be obtained from a biopsy or during PPV. In addition, the mechanical trauma associated with PPV may limit the use of the sample. ${ }^{7}$ In addition, 
if steroid therapy had been performed, the cellular necrosis induced will prevent any useful cytological analysis of fluids collected during PPV. ${ }^{8}$

We have reported that infusion fluid can be used for the cytological diagnosis of sarcoidosis. ${ }^{9}$ The purpose of this paper is to report two cases of intraocular lymphoma diagnosed with the results obtained from cytokine and cytological analyses of the vitreous and infusion fluid collected during PPV.

\section{Case I}

A 66-year-old woman was referred to our hospital complaining of floaters in both eyes in February 2010. At the initial examination, her best-corrected visual acuity (BCVA) was 20/25 in both eyes, and diffuse vitreous opacifications with aggregation of large cells were present in both eyes (Figure 1A and B). Fluorescein angiography showed no abnormalities. The results of the laboratory examinations were within normal limits. Cerebral magnetic resonance imaging (MRI) detected no abnormalities.

Although she was treated with corticosteroid therapy for 3 months, her VA had decreased to 20/50 in both eyes with increased vitreous opacification. She then underwent PPV by the standard three-port approach (20-gauge). The core vitreous was cut with a vitreous cutter, and about $1 \mathrm{~mL}$ of undiluted vitreous was collected by simultaneous manual aspiration. After the infusion line was opened, a full PPV was done, and the cortical vitreous was removed as much as possible. The undiluted vitreous was immediately frozen
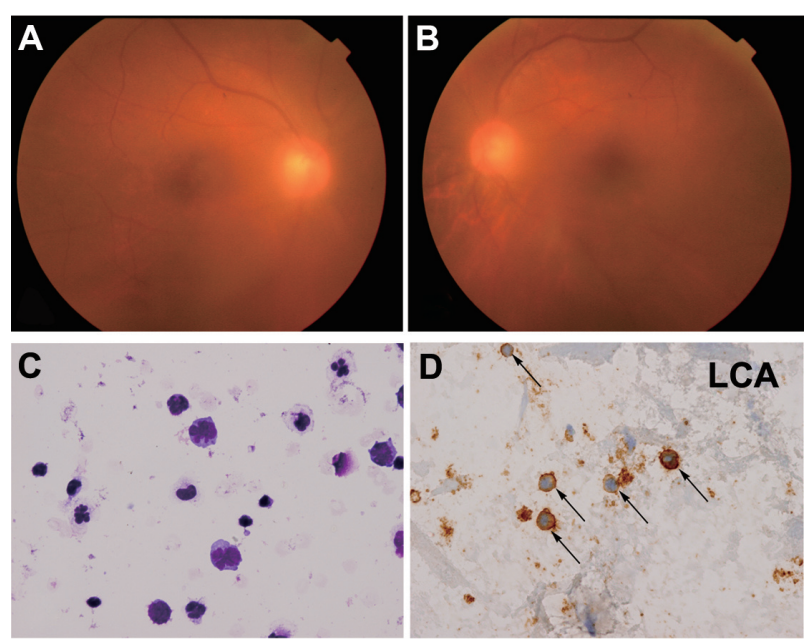

Figure I Fundus photographs and cytological examination of Case I. Fundus photographs of (A) right and (B) left eye at the initial examination. Diffuse vitreous opacification can be seen in both eyes. (C) Atypical lymphocytes with anisonucleosis, aberrant chromatin, and dyskaryosis. Giemsa stain (400x). (D) Immunocytochemical findings (400x).

Note: Lymphoma cells are positive for leukocyte common antigen (LCA; arrows). at $-20^{\circ} \mathrm{C}$, and submitted for cytokine analysis. Infusion fluid (BSS PLUS ${ }^{\circledR}$; Alcon Japan Ltd., Tokyo, Japan) used during full PPV was obtained from the machine cassette (Fortas ${ }^{\mathrm{TM}}$ CV-30000; Nidek Co, LTD, Aichi, Japan) after the surgery (about $300 \mathrm{~mL}$ ), and immediately submitted for cytological analysis with use of cytospin.

Atypical lymphocytes with anisonucleosis, aberrant chromatin, and dyskaryosis were detected by cytological analysis (Figure 1C). The lymphoma cells were positive for leukocyte common antigen (LCA: Figure 1D). The ratio of interleukin (IL)-10 to IL-6 (IL-10/IL-6 ratio) of the undiluted vitreous was greater than 1.0 (IL-10 $=7650 \mathrm{pg} / \mathrm{mL}$ : IL-6 = $139 \mathrm{pg} / \mathrm{mL}$ ). She was diagnosed with primary intraocular lymphoma in both eyes and received intravitreal and intraspinal methotrexate therapy. At 3 years after the surgery, the vitreous opacification had disappeared and her corrected VA had improved to 20/20.

\section{Case 2}

A 62-year-old man was referred to our hospital with reduced vision in February 2012. He was diagnosed with central retinal vein occlusion of the left eye (Figure 2A and B), and diabetic retinopathy in both eyes, and diffuse large B-cell lymphoma of the paranasal sinuses (Figures 2C and 3) in November 2008. He received chemotherapy at the Department of Internal Medicine of our hospital, which led to a remission of the lymphoma.

At our initial examination, his BCVA was 20/20 in right eye and 20/25 in left eye. The anterior chamber was not inflamed, but diffuse vitreous opacification with aggregation

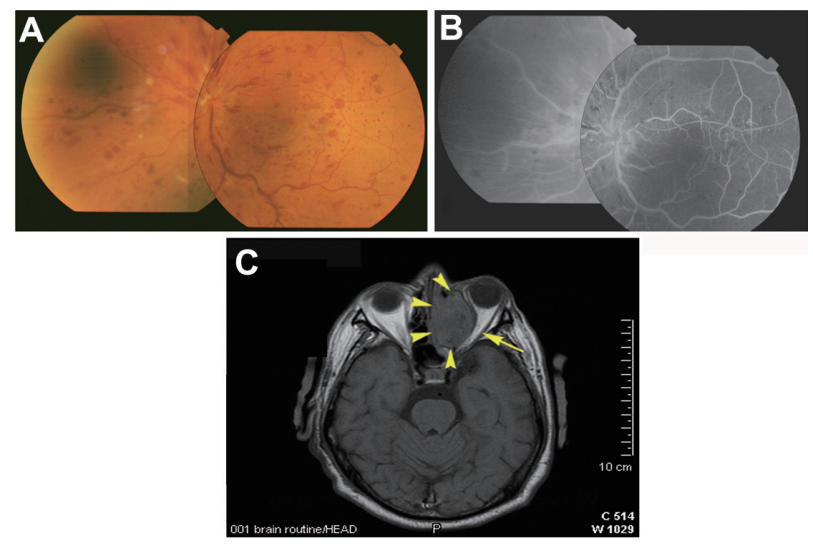

Figure 2 Fundus photographs, fluorescein angiograms, and cerebral MRI of Case 2 obtained in 2008. (A) Central retinal vein occlusion can be seen in left eye: hyperemic swollen papilla, engorged veins, streaky retinal bleedings, and cottonwool spots. (B) Fluorescein angiograms showing staining of the walls of large veins, and no nonperfused areas in the left eye. (C) Cerebral MRI shows the tumor in paranasal sinuses (arrow heads), compressed optic nerve (arrow), and proptosis of the left eye.

Abbreviation: MRI, magnetic resonance imaging. 


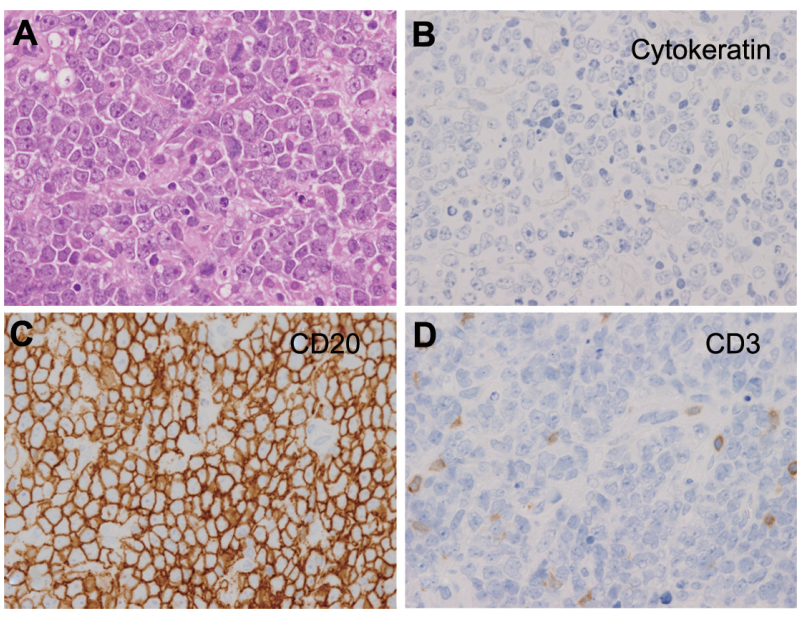

Figure 3 Histopathological examination of paranasal-sinuses tumor of Case 2. $(400 \times)($ A) Atypical cells with anisonucleosis, aberrant chromatin, and dyskaryosis. Giemsa stain. Immunocytochemical findings. The cells are negative for T-lymphocyte surface antigen (CD3). (B) Immunocytochemical findings. The cells are negative for cytokeratin (AEI/AE3), a marker of epithelial cells. (C) Immunocytochemical findings. The cells are positive for B-lymphocyte surface antigen (CD20). (D) Immunocytochemical findings. The cells are negative for T-lymphocyte surface antigen (CD3).

of large cells was observed in right eye, and dot hemorrhages were observed in both eyes. Fluorescein angiography showed several small nonperfused areas, but no retinal neovascularization. The results of laboratory examinations were essentially normal except high blood glucose level. Cerebral MRI and positron emission tomography (PET) did not detect any abnormalities. The lymphoma in his right eye was suspected to be a metastasis because of the history of paranasal lymphoma and the ocular findings. Therefore, he underwent PPV on the right eye. Vitreous samples and infusion fluid were collected as in Case 1 .

From the infusion fluid, atypical lymphoid cells with large and irregular nuclei and prominent nucleoli were detected by cytological analysis (Figure 4A and B). Immunohistochemistry showed that the cells were positive for B-lymphocyte surface antigen (CD20) and negative for T-lymphocyte surface antigen (CD3) (Figure 4C and D). The IL-10/IL-6 ratio of the undiluted vitreous was greater than $1.0(\mathrm{IL}-10=48 \mathrm{pg} / \mathrm{mL} ; \mathrm{IL}-6=9.0 \mathrm{pg} / \mathrm{mL})$. Immunoglobulin heavy chain $(\mathrm{IgH})$ gene rearrangements were detected in the undiluted vitreous. He was diagnosed with metastatic intraocular lymphoma in the right eye and received irradiation therapy. At 1 year after the surgery, his BCVA had improved to $20 / 20$ in both eyes.

\section{Discussion}

We report two cases in which an intraocular lymphoma was diagnosed from cytokine and cytological analyses of vitreous and infusion fluid collected during PPV. The undiluted

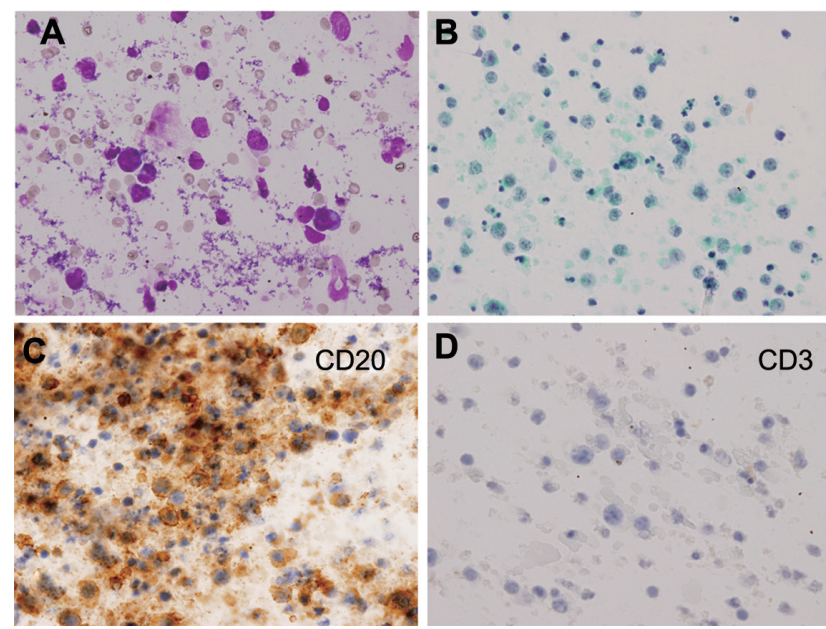

Figure 4 Cytological examination of infusion fluid of Case 2 (400x). (A and B) Atypical lymphocytes with anisonucleosis, aberrant chromatin, and dyskaryosis. (A) Giemsa stain; (B) Papanicolaou stain. (C) Immunocytochemical findings. Lymphoma cells are positive for B-lymphocyte surface antigen (CD20). (D) Immunocytochemical findings. Lymphoma cells are negative for T-lymphocyte antigen (CD3).

vitreous was used for cytokine analysis, and the infusion fluid for cytological analysis.

Generally, the undiluted vitreous obtained from core PPV or vitreous biopsy is submitted for cytological analysis in cases suspected of having an intraocular lymphoma. Submitting infusion fluid obtained from full PPV for cytological examination has four advantages. First, a larger number of cells can be collected. Mudhar et al reported that the lymphoma cells were concentrated more in the cortical vitreous than core vitreous. ${ }^{10}$ Additionally, Conlon et al reported that vitrectomy did not cause any more cellular degradation than simple aspiration. ${ }^{11}$ In our cases, we were able to obtain a sufficient volume of lymphoma cells from the infusion fluid.

The second advantage is that undiluted vitreous can be submitted for other examination, such as cytokine analysis, IgH gene arrangements, and flow cytometry. Several studies have reported that cytokine analysis of vitreous had the highest detection rate for intraocular lymphomas., 3 However, the amount of undiluted vitreous obtained from PPV or vitreous biopsy is usually too small to be submitted for several types of analyses. Therefore, undiluted vitreous can be submitted for cytokine analysis, if the infusion fluid is submitted for cytological analysis. ${ }^{12}$

The third advantage is that the cell collection rate can be increased by cytospin of the infusion fluid, and the collected cells can be used for the cytological analysis. Undiluted vitreous is not as effective for collecting cells by cytospin because of its high viscosity. In contrast, the infusion fluid 
is not as viscous and does contain diluted cortical vitreous, which allowed us to collect more cells.

Finally, infusion fluid contains cellular protectants such as oxidized glutathione and glucose. ${ }^{13}$ The lymphoma cells are fragile because of mechanical trauma associated with PPV and cellular necrosis induced by steroid therapy. These changes can be reduced by the cellular protectants.

There are limitations to this report. Lymphoma cells are known to infiltrate the vitreous, subretinal pigment epithelium, retina, choroid, iris, and optic nerve. ${ }^{3,5,8}$ In some cases of intraocular lymphomas, tumor masses in the subretinal pigment epithelium position can only be observed without vitreous infiltration. In those cases, only analysis of vitreous and infusion fluid may be difficult to detect lymphoma cells without chorioretinal biopsy. ${ }^{5}$

In conclusion, we found that undiluted vitreous and infusion fluid collected during full PPV could be used for cytokine and cytological analyses for diagnosing intraocular lymphomas.

\section{Acknowledgments/disclosure}

None of the authors report any conflicts of interest associated with this work.

\section{References}

1. Bardenstein DS. Intraocular lymphoma. Cancer Control. 1998;5: 317-325.

2. Goto H, Mochizuki M, Yamaki K, et al. Epidemiological survey of intraocular inflammation in Japan. Jpn J Ophthalmol. 2007;51:41-44.
3. Kimura K, Usui Y, Goto H. Clinical features and diagnostic significance of the intraocular fluid of 217 patients with intraocular lymphoma. Jpn J Ophthalmol. 2012;56:383-389.

4. Jahnke K, Korfel A, Komm J, et al. Intraocular lymphoma 2000-2005: results of a retrospective multicentre trial. Graefes Arch Clin Exp Ophthalmol. 2006;244:663-669.

5. Gonzales JA, Chan CC. Biopsy techniques and yields in diagnosing primary intraocular lymphoma. Int Ophthalmol. 2007;27:241-250.

6. Michels RG, Knox DL, Erozan YS, et al. Intraocular reticulum cell sarcoma. Diagnosis by pars plana vitrectomy. Arch Ophthalmol. 1975;93:1331-1335.

7. Char DH, Ljung BM, Miller T, et al. Primary intraocular lymphoma (ocular reticulum cell sarcoma) diagnosis and management. Ophthalmology. 1988;95:625-630.

8. Whitcup SM, de Smet MD, Rubin BI, et al. Intraocular lymphoma. Clinical and histopathologic diagnosis. Ophthalmology. 1993;100: 1399-1406.

9. Matsuoka M, Ogata N, Takahashi K, et al. Two cases of ocular sarcoidosis in which vitreous cytology was useful for supporting the diagnosis. Clin Ophthalmol. 2012;6:1207-1209.

10. Mudhar HS, Sheard R. Diagnostic cellular yield is superior with full pars plana vitrectomy compared with core vitreous biopsy. Eye (Lond). 2013;27:50-55.

11. Conlon MR, Craig I, Harris JF, et al. Effect of vitrectomy and cytopreparatory techniques on cell survival and preservation. Can $J$ Ophthalmol. 1992;27:168-171.

12. Kinoshita Y, Takasu K, Adachi Y, et al. Retrospective cytological study of intraocular lymphoma using vitreous and intraocular perfusion fluid. Diagn Cytopathol. 2010;40:604-607.

13. Araie M, Shirasawa E, Hikita M. Effect of oxidized glutathione on the barrier function of the corneal endothelium. Invest Ophthalmol Vis Sci. 1988;29:1884-1887.
Clinical Ophthalmology

\section{Publish your work in this journal}

Clinical Ophthalmology is an international, peer-reviewed journal covering all subspecialties within ophthalmology. Key topics include: Optometry; Visual science; Pharmacology and drug therapy in eye diseases; Basic Sciences; Primary and Secondary eye care; Patient Safety and Quality of Care Improvements. This journal is indexed on Submit your manuscript here: http://www.dovepress.com/clinical-ophthalmology-journal

\section{Dovepress}

PubMed Central and CAS, and is the official journal of The Society of Clinical Ophthalmology (SCO). The manuscript management system is completely online and includes a very quick and fair peer-review system, which is all easy to use. Visit http://www.dovepress.com/ testimonials.php to read real quotes from published authors. 